
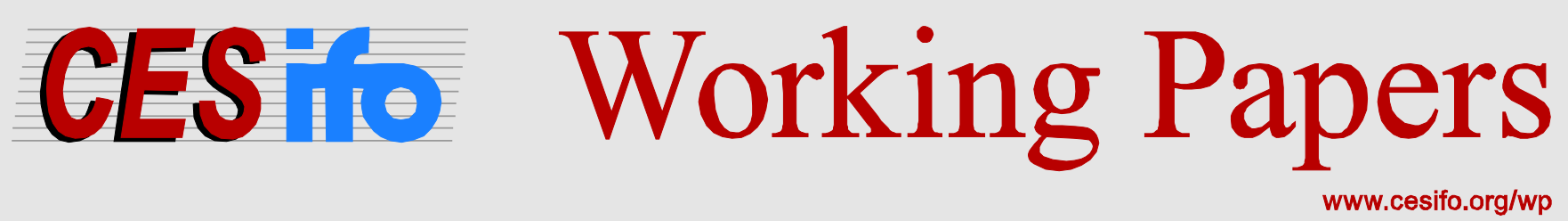

\title{
Optimal Cost Overruns: Procurement Auctions and Renegotiation
}

\author{
Fabian Herweg \\ Marco A. Schwarz
}

CESIFO WORKING PAPER NO. 5838

CATEGORY 11: INDUSTRIAL ORGANISATION

MARCH 2016
An electronic version of the paper may be downloaded
- from the SSRN website:
- from the RePEc website:
- from the CESifo website:
www.SSRN.com
www.RePEc.org
www.CESifo-group.org/wp




\title{
Optimal Cost Overruns: Procurement Auctions and Renegotiation
}

\begin{abstract}
Cost overrun is ubiquitous in public procurement. We argue that this can be the result of a constraint optimal award procedure when the procurer cannot commit not to renegotiate. If cost differences are more pronounced for more complex designs, it is optimal to fix a simple design ex ante and to renegotiate to a more complex and costlier design ex post. Specifying a simple design initially enhances competition in the auction. Moreover, the procurer cannot benefit from using a multi-dimensional auction, as the optimal scoring rule depends only on the price.
\end{abstract}

JEL-Codes: D440, D820, H570.

Keywords: auction, cost overrun, procurement, renegotiation.

\author{
Fabian Herweg \\ University of Bayreuth \\ Faculty of Law, Business and Economics \\ Universitätsstr. 30 \\ Germany - 95440 Bayreuth \\ fabian.herweg@uni-bayreuth.de
}

\author{
Marco A. Schwarz \\ University of Munich \\ Department of Economics \\ Ludwigstr. 28 (Rgb.) \\ Germany-80539 Munich \\ marco.schwarz@econ.Imu.de
}

This version: March 18, 2016

We thank Mikhail Anufriev, Jacob Goeree, Heiko Karle, Laurent Lamy, Laurent Linnemer, Johannes Maier, Antonio Rosato, and Klaus Schmidt for many helpful comments and suggestions. We would also like to thank seminar participants at X-CREST Paris, University of Bern, LMU Munich, and University of Technology Sydney. Part of this research was conducted while the first author visited University of Technology Sydney and Fabian would like to thank the Business School for its great hospitality. 


\section{Introduction}

Renegotiation of procurement contracts awarded by public authorities are ubiquitous. The initial contract is awarded via competitive tendering; i.e., via an auction. The terms of the initial contract, however, are often subject to renegotiation with the result that the ultimate price is (by far) higher than the price which the parties initially agreed upon. Prominent recent examples of public procurement projects that are by far more expensive than initially planned are the Elbphilharmonie, a concert hall in Hamburg, the Big Dig, a highway artery in Boston, and the North-South metro line in Amsterdam. $]^{1}$ What is often considered as the most severe case of a cost overrun in modern construction history is the Sydney Opera House..$^{2}$ The project was completed 10 years late at a price of 14.6 times the initial price $3^{3}$ During the construction of the Sydney Opera House, plenty of design changes had taken place. For instance, the change to the ribbed ellipsoidal roof increased the cost for the roof by $65 \%$. Also the use of the two halls changed during construction. The major hall was originally planned as a multipurpose opera/concert hall but became solely a concert hall (the Concert Hall). The minor hall, called the Joan Sutherland Theatre today, had been adjusted so that it can incorporate opera performances. All these changes that arguably made the Sydney opera House more complex are responsible for a large part of its cost overrun. 4

While the costs of complex and large-scale projects are hard to estimate, the ultimate price should on average coincide with the initial estimates if the estimates are unbiased. Casual observations and empirical studies, however, suggest that the prices typically increase through renegotiation. 5 According to public opinion, these cost overruns are

${ }^{1}$ Regarding the Elbphilharmonie the accepted offer from the underwriting group in 2006 was 241 million euro. The current costs are estimated at around 800 million euro and the project is not yet completed (Kostka and Anzinger, 2015). For the Amsterdam metro line the initial budget was set at 1.46 billion euro in 2002 but the costs had risen to 3.1 billion euro in 2009. Recent estimates suggest that it will be completed in 2017 (Chang, Salmon, and Saral, 2014). For the Boston highway artery the ultimate price exceeded the initial price by 1.6 billion US dollar (Bajari, Houghton, and Tadelis. 2014).

${ }^{2}$ We define as cost overrun the difference between the final price and the initial price at which the procurement order has been awarded.

${ }^{3}$ When controlling for inflation, the cost overrun reduces to a factor of 7.5 Newton, Skitmore, and Love, 2014).

${ }^{4}$ See Newton, Skitmore, and Love (2014) and Drew (1999) for more detailed discussions of the construction and cost increases of the Sydney Opera House.

${ }^{5}$ Substantial price increases resulting from contract renegotiation are reported by Decarolis (2014) for Italian procurement contracts and by Bajari, Houghton, and Tadelis (2014) for Californian procurement contracts. German procurement contracts and the their cost increases are listed by Kostka and Anzinger (2015). They also report that some projects perform exceptionally well. For instance, the 
sign of inefficient project management by bureaucrats or strategizing politicians and a waste of taxpayers' money. In contrast to this widespread public opinion, we argue that these seemingly inefficient cost overruns can be the result of a constraint optimal award procedure that minimizes the expected final price for the procurer.

The baseline model is fairly simple. A procurer needs an indivisible good or service, which can take one of several designs; i.e., the good can be more or less complex (a bridge with two or three traffic lanes). The good can be delivered by several suppliers that may differ in their privately known production costs. Moreover, the ex post efficient design depends on the contractor's production cost - i.e., on the cost type of the supplier who has been awarded with the contract. Initially the procurer runs an auction in order to allocate the contract. Importantly, the contract specified by the auction is a specific performance contract that can be enforced by courts. First, we assume that the procurer can collect bids only on prices and thus has to select one particular design of the good. More precisely, the procurement contract for the given design is awarded to one supplier via a standard second price sealed bid auction. The design given in the initial contract may turn out to be inefficient, given the cost type of the contractor. In this case, we assume that the parties engage in Coasian bargaining and implement the efficient good ex post. Renegotiation is expected by the suppliers and thus incorporated in their bidding behavior. The rent the contractor (the supplier who won the auction) receives depends on his cost advantage compared to the second-lowest bidder with regard to the initial design. If cost differences are more pronounced for more complex designs, than it is optimal for the procurer to fix a rather simple design ex ante because this enhances competition in the initial auction. In other words, when commitment not to renegotiate is not feasible, it is optimal for the procurer to choose a simple design ex ante and to renegotiate to a more complex and costlier design ex post. The outcome is efficient because the supplier with the lowest cost wins the auction. He can not only produce the initial design at lower cost but also benefits more from contract renegotiation than suppliers with higher costs. Moreover, the outcome is constraint optimal for the procurer because it minimizes the ultimate price she has to pay.

In an extension we allow the procurer to set a public maximum bid. We show that our main findings are robust regarding the introduction of a maximum bid. It is still

Chemikum, a building of the University of Erlangen-Nuremberg, was completed a year earlier than planned and at a cost of only 80 million euro instead of the planned 140 million euro. 
optimal to choose a simple design ex ante so that contract renegotiation always leads to a more complex design which requires an upward price adjustment.

In our general model, we allow for multi-dimensional auctions - i.e., scoring auctions. The procurer now asks for bids containing a price and a design. The supplier who places the bid leading to the highest score - determined by a commonly known scoring rule - wins the auction. The procurer's initial choice is the scoring function, which we restrict to be linear in price. If the scoring function reflects the procurer's true preferences, each supplier offers the optimal design given his cost. In this case, contract renegotiation can be avoided. The optimal scoring function, however, does not reflect the procurer's true preferences. It depends solely on the price offer and not on the offered design. Thus, all suppliers offer the most simple and cheapest design. The most efficient supplier wins the initial auction and the parties agree to implement a more complex design at a higher price ex post via renegotiation. In other words, a standard auction for the simplest design (only price bids are collected) outperforms scoring auctions, where suppliers place multi-dimensional bids containing a price and a design. The reason is that a multi-dimensional auction allows for differentiation of the suppliers' bids, which relaxes competition between suppliers ex ante and thus leads to higher ultimate prices. This finding is in contrast to the existing literature on scoring auction that assumes the procurer can commit not to renegotiate the contract (Dasgupta and Spulber, 1989-1990; Che, 1993, Chen-Ritzo, Harrison, Kwasnica, and Thomas, 2005).

As a robustness, we analyze what happens when there is an exogenous risk that the renegotiation breaks down and the parties are stuck with the initial contract. If this risk is rather low, it is still optimal to choose a simple design ex ante. As the risk becomes larger, taking into account the situation when renegotiation fails becomes more important, so the optimal design becomes more complex and closer to the ex post optimal design. However, as we demonstrate in an example, upward price adjustments seem to be by far more likely than downward price adjustments if renegotiation takes place; i.e., if there had been a risk of bargaining breakdown but the parties succeed in finding an agreement.

The paper is structured as follows. After having discussed the related literature, which is done in the following paragraphs, we introduce the model in Section 2, The model is analyzed in Section 3. This section concludes with our first main finding; rene- 
gotiation of the contract determined by the constraint optimal auction always leads to an upward price adjustment (Proposition 1). We extend the baseline model and allow for multi-dimensional auctions in Section 4, where we show that price-only auctions are optimal (Proposition 3). We critically discuss our assumptions in Section 5 and, in particular, show that our main findings are robust toward introducing a risk of bargaining breakdown. The final Section 6 summarizes our findings and concludes. All proofs that are not presented in the main text are deferred to the Appendix A.

\section{Related Literature}

Investigation of procurement contracts is an important and classic topic of contract theory $\left.\right|^{6}$ A seminal contribution analyzing procurement and renegotiation is Tirole (1986). He analyzes the contractual relationship between a single procurer and a single supplier with a focus on how initial contracts can enhance non-contractible relationship specific investments.

Dasgupta and Spulber (1989-1990), Che (1993), and Chen-Ritzo, Harrison, Kwasnica, and Thomas (2005) analyze procurement auctions for the case that the procurer can commit not to renegotiate the contract. All three articles show that the optimal scoring auction outperforms price-only auctions. We demonstrate that if this commitment is absent, the optimal price-only auction outperforms scoring auctions.

There is only a small extent literature that analyzes auctions without perfect commitment; i.e. that allow either bidders to renege on their bids or to engage in contract renegotiation.7 Waehrer (1995), Harstad and Rothkopf (1995), and Roelofs (2002) allow bidders to withdraw the winning bid ex post. In these models suppliers are initially uncertain about their costs and thus may underestimate it. The possibility to default on the initial commitments enhances competition in the auction, which in turn is beneficial to the procurer. 8 Waehrer (1995) also analyzes a scenario where the procurer and the winner renegotiate a new contract. Here, however, renegotiation takes place after the default of the winner and thus the initial contract has no impact on the outcome of

\footnotetext{
${ }^{6}$ For an excellent discussion of the standard contract theoretical analysis of procurement see Laffont and Tirole (1993).

${ }^{7}$ There is also a small literature that analyzes screening mechanisms if the principal (the procurer) cannot commit not to renegotiate; e.g. Beaudry and Poitevin(1995). This literature typically assumes that there is only one buyer and one seller and focuses on the constraints limited commitment power imposes on the implementable allocations.

${ }^{8}$ The effects of limited liability on more general mechanisms than auctions are investigated by Burguet, Ganuza, and Hauk (2012).
} 
renegotiation.

A similar form of renegotiation is analyzed by Wang (2000) and Shachat and Tan (2015). In these models the procurer either accepts the lowest bid or rejects all bids. In case of rejection, the procurer negotiates with the supplier who placed the lowest bid; i.e. if renegotiation takes place the initial contract concluded by the auction is not binding. In such a setup renegotiation always leads to lower prices, which is exactly the opposite from what we study.

The initial contract has an impact on the outcome of renegotiation in Chang, Salmon, and Saral (2014). Here, suppliers' production costs have an ex-ante unknown common component. Some of the suppliers are wealth constraint, while other have deep pockets and this is private information of each supplier. Allowing for contract renegotiation is advantageous to wealth-constraint suppliers who can credibly threaten to default. The prices increase with renegotiation in order to avoid bankruptcy of the contractor who is faced by unexpectedly high costs. In our model, the parties agree to a different design of the project ex post, which is more costly to produce and thus the final price exceeds the initial price.

A few papers directly deal with the issue of cost overruns. Birulin and Izmalkov (2013) analyze what shares of a price are optimally paid before and after a potential extra cost to the supplier realizes, when suppliers are protected by limited liability. This paper is orthogonal to ours, because it does not provide an explanation for cost overruns but rather assumes its existence.9 Closer to our work is Ganuza (2007). Here, suppliers are differentiated à la Salop (1979). The buyer does not know her preferences - her location - but can invest in obtaining a noisy signal. A procurement order for the expected optimal design is awarded via a price-only auction. Ex post, the buyer's preference is common knowledge and the winner of the auction can make a take-it-orleave-it renegotiation offer. The main result is that the buyer under-invests in learning her preferences because this enhances competition in the initial auction. This is related to our results that the initial design is choose to enhance competition in the initial auction. There are, however, crucial differences. For instance, in our model the buyer's preferences are known ex ante and suppliers are not horizontally differentiated.

Finally, costly renegotiation of incomplete procurement contracts is analyzed by $\mathrm{Ba}-$ jari and Tadelis (2001) and Herweg and Schmidt (2014). The former paper analyzes

\footnotetext{
${ }^{9} \mathrm{~A}$ similar model is analyzed by $\overline{\text { Birulin }}(2014)$.
} 
when fixed-price contracts outperform cost-plus contracts, while the latter one derives conditions so that bilateral negotiations outperform procurement auctions ${ }^{10}$

\section{The Model}

\subsection{Players and Payoffs}

A procurer $P$, say a government agency, wants to buy one unit of an indivisible good, e.g., a bridge. The good can be produced with one of various designs $x \in\left\{x_{1}, \ldots, x_{J}\right\} \equiv$ $X$, with $J \geq 2$. The procurer's valuation of the good depends on the design $x$ and is denoted by $v(x)$. There are $n \geq 2$ suppliers, indexed by $i=1, \ldots, n$, that can produce the good required by the procurer. A supplier's production cost depend on the design $x$ and his cost type $\theta \in[\underline{\theta}, \bar{\theta}] \equiv \Theta$, and is denoted by $c(x, \theta)$. Ex ante, the cost type $\theta$ is private information of each supplier. The $n$ cost types are drawn independently according to the identical cumulative distribution function $F(\theta)$. Let the corresponding probability density be $f(\theta)$, with $f(\theta)>0$ for all $\theta \in \Theta$. When design $x$ is delivered at price $p$, the procurer's and the contractor's, i.e., the selected supplier's, ex post utilities are

$$
\begin{aligned}
u & =v(x)-p \\
\text { and } \pi & =p-c(x, \theta),
\end{aligned}
$$

respectively. All parties are assumed to be risk neutral and the outside option utilities are all set equal to zero.

For the remainder of the paper, we denote the ex post efficient design by

$$
x^{*}(\theta) \in \arg \max _{x \in X}\{v(x)-c(x, \theta)\}
$$

and the corresponding social surplus by

$$
S(\theta)=\max _{x \in X}\{v(x)-c(x, \theta)\}
$$

We make the following assumptions on the designs, the procurer's valuation, and the suppliers' cost functions. We posit that the designs can be ordered so that a higher

\footnotetext{
${ }^{10}$ An empirical analysis of incomplete procurement contracts is provided by Crocker and Reynolds (1993). They argue that contracts are left incomplete intentionally to economize on the cost of the ex ante design.
} 
design leads to a higher gross benefit for the procurer but is more costly to produce for the suppliers. ${ }^{11}$

Assumption 1 (designs are ordered). For all $j \in\{1, \ldots, J-1\}$ and all $\theta \in \Theta$ :

(i) $v\left(x_{j}\right) \leq v\left(x_{j+1}\right)$;

(ii) $c\left(x_{j}, \theta\right) \leq c\left(x_{j+1}, \theta\right)$.

Regarding the impact of the type $\theta$ on the production cost, we assume that lower types are more efficient.

Assumption 2 (Types are ordered). For all $\theta_{1}, \theta_{2} \in \Theta$ with $\theta_{1}<\theta_{2}$ and all $x \in X$ :

$$
c\left(x, \theta_{1}\right)<c\left(x, \theta_{2}\right) .
$$

Assumption 2 implies that $S(\theta)$ is decreasing 12

Finally, we assume that the cost advantage is lowest for the cheapest design $x_{1}$. For more complex designs, the differences in costs between suppliers of different types are larger.

Assumption 3 (Increasing differences). For all $\theta_{1}, \theta_{2} \in \Theta$ with $\theta_{1}<\theta_{2}$ and all $x \in$ $X \backslash x_{1}$ it holds that:

$$
c\left(x, \theta_{2}\right)-c\left(x, \theta_{1}\right)>c\left(x_{1}, \theta_{2}\right)-c\left(x_{1}, \theta_{1}\right)
$$

This assumption is weaker than assuming that the cost advantage is increasing in the complexity of the design; i.e., assuming that the costlier the design is the more important it is to select the most efficient supplier. ${ }^{13}$ The latter assumption corresponds to the usual single-crossing property, which is a standard assumption in the auction literature (Krishna, 2010).

\footnotetext{
${ }^{11}$ Designs that lead to higher costs and lower benefits than some other design, will never be implemented. All the designs that are not dominated by another design can be ordered so that higher elements are associated with higher benefits and higher costs. Thus, Assumption 1 is merely a relabeling of the designs.

${ }^{12}$ We impose Assumption 2 for simplicity but it is not necessary. In fact, we can allow for $c\left(x, \theta_{1}\right)>$ $c\left(x, \theta_{2}\right)$ for some $x$, as long as $S\left(\theta_{1}\right)$ is sufficiently larger than $S\left(\theta_{2}\right)$.

${ }^{13}$ Formally: For all $\theta_{1}<\theta_{2}$ and $x_{l}, x_{H} \in X$ with $L<H$ :
}

$$
c\left(x_{H}, \theta_{2}\right)-c\left(x_{H}, \theta_{1}\right)>c\left(x_{L}, \theta_{2}\right)-c\left(x_{L}, \theta_{1}\right) .
$$




\subsection{Award Procedure and Renegotiation}

The procurement contract is awarded to one supplier, called the contractor, via an auction. For now, we assume that the procurer has to use a simple auction; i.e. a second price sealed bid auction without maximum bid for a pre-specified design $\bar{x} \in X{ }^{14}$ In other words, the procurer can collect only price bids for a given design. A scoring auction which maps bids containing a price and a design into a single score cannot be used. This could be due to the fact that the different designs are hard to describe and thus a scoring function cannot be formulated. Moreover, we assume that the used procurement mechanism is a second-price sealed bid auction without maximum bid. Not specifying a maximum bid is optimal if the procurer has to buy the good for sure i.e., the bridge is urgently needed and thus the loss in surplus is huge if no construction contract is signed.

When specifying the initial auction, the procurer has only one choice variable, the design $\bar{x} \in X$. The procurement order for the good with design $\bar{x} \in X$ is auctioned off between the $n$ suppliers. Each supplier $i$ places a secret price bid $p_{i}$. The supplier with the lowest bid is selected as the contractor and the specified price equals the second lowest bid. If the lowest bid is made by several suppliers, one of these suppliers is selected at random as the contractor.

With the procurer being restricted to simple auctions and suppliers' types being stochastic, the initial design $\bar{x}$ may not be optimal given the contractor's type ex post. In this case there is scope for renegotiation. We posit that the contractor's type becomes common knowledge ex post and thus the parties engage in Coasian bargaining ex post ${ }^{15}$ The surplus from renegotiation is split between the procurer and the contractor according to the generalized Nash bargaining solution (GNBS), i.e. the renegotiation contract is

$$
(\hat{x}, \hat{p}) \in \arg \max _{x \in X, p \in \mathbb{R}}\left[p-c(x, \theta)-d_{C}\right]^{\alpha} \times\left[v(x)-p-d_{P}\right]^{1-\alpha},
$$

where $\alpha \in(0,1)$ denotes the contractor's relative bargaining power ex post ${ }^{16}$ The

\footnotetext{
${ }^{14}$ The restriction to a second price auction is without loss of generality because the revenue equivalence theorem holds in our model. This implies in particular that the main propositions also hold in case of a first price auction. The restriction to simple auctions - i.e., neither a maximum bid nor a scoring auction, is relaxed in Section 5

${ }^{15}$ The procurer might receive a signal about the contractor's type due to interaction with the contractor or information acquisition which would have been too costly at an earlier stage. We focus on the extreme case in which the contractor's type is fully revealed.

${ }^{16}$ For a detailed description of the Nash bargaining solution see Muthoo (1999). A non-cooperative foun-
} 
disagreement payoffs of the two parties are determined by the initial contract $(\bar{x}, \bar{p}) \cdot 17$

$$
\begin{aligned}
d_{C} & =\bar{p}-c(\bar{x}, \theta) \\
d_{P} & =v(\bar{x})-\bar{p} .
\end{aligned}
$$

The sequence of events is described in Figure 1. We employ perfect Bayesian equilibrium in symmetric strategies as equilibrium concept.

- Nature draws $\theta_{1}, \ldots, \theta_{n}$.

- Procurer selects $\bar{x}$ and auctions off contract.
- Suppliers submit bids.

- Lowest bidder wins contract $(\bar{x}, \bar{p})$, where $\bar{p}$ is the second lowest bid.

Figure 1: Timeline.
- Contractor's cost type is observed by procurer.

- Parties may renegotiate to a new contract $(\hat{x}, \hat{p})$.

\section{The Analysis}

\subsection{Contract Renegotiation and Bidding Behavior}

We start the analysis with the renegotiation game. Suppose the procurer awarded a supplier with cost type $\theta$ with the contract $(\bar{x}, \bar{p})$. If the design $\bar{x}$ is not the efficient design given the contractor's cost type, $\bar{x} \neq x^{*}(\theta)$, then there is scope for renegotiation. The social surplus can be increased by moving $\bar{x}$ to $x^{*}(\theta)$ and this additional surplus is split between the two parties according to their relative bargaining power. The outcome of renegotiation is characterized in the following lemma.

Lemma 1 (Renegotiation outcome). Let $(\bar{x}, \bar{p})$ be the initial contract and suppose the contractor's cost type is $\theta$. Ex post, the procurer and the contractor agree to trade design $\hat{x}=x^{*}(\theta)$ at price

$$
\hat{p}=\bar{p}+\alpha\left[v\left(x^{*}(\theta)\right)-v(\bar{x})\right]+(1-\alpha)\left[c\left(x^{*}(\theta), \theta\right)-c(\bar{x}, \theta)\right]
$$

A supplier taking part in the auction is aware that the contract may be renegotiated ex post. In particular, he knows that if he wins the auction, he may obtain additional profits generated by contract renegotiation. These additional profits from renegotiation

dation for the Nash bargaining solution is provided by Binmore, Rubinstein, and Wolinsky (1986).

${ }^{17}$ Exactly the same findings are obtained with an alternative bargaining game, where the GNBS is replaced by a take-it-or-leave-it offer game. With probability $\alpha$ the contractor can make a take-it-orleave-it offer in the renegotiation game, with probability $(1-\alpha)$ the procurer can. 
are incorporated in a supplier's bidding behavior. Supplier $\theta$ 's ex post payoff from being awarded with the procurement contract $(\bar{x}, \bar{p})$ is

$$
\begin{aligned}
\pi(\bar{x}, \bar{p}, \theta) & =\hat{p}(\bar{p}, \theta)-c\left(x^{*}(\theta), \theta\right) \\
& =\bar{p}+\alpha\left[v\left(x^{*}(\theta)\right)-c\left(x^{*}(\theta), \theta\right)\right]-\alpha v(\bar{x})-(1-\alpha) c(\bar{x}, \theta) .
\end{aligned}
$$

The price bid affects directly the probability of winning the auction but only indirectly the price the supplier receives when being awarded with the contract. Thus, placing the lowest feasible bid that allows the supplier to break-even, even when he is awarded with the contract at a price equal to his bid, is optimal. The equilibrium bidding behavior is formally described in the next lemma.

Lemma 2 (Outcome of the auction). Suppose that Assumption 2 holds and that the procurement order for design $\bar{x}$ is awarded via a second price sealed bid auction. In the unique equilibrium in undominated strategies, each supplier uses the bidding function

$$
\bar{p}(\theta)=\alpha v(\bar{x})+(1-\alpha) c(\bar{x}, \theta)-\alpha S(\theta)
$$

and the supplier with the lowest type wins the auction.

It is important to note that - according to Lemma 2 - the auction selects the most efficient supplier. In other words, productive efficiency is still guaranteed by a second price auction even if contract renegotiation is feasible. This relies on the fact that a more efficient type has not only lower production costs for producing design $\bar{x}$ but also generates a higher surplus by adjusting the design via contract renegotiation.

\subsection{Constraint Optimal Auction}

The procurer does not only care about ex post efficiency but also about the ultimate price she has to pay for the good. The initial price - i.e., the price specified in the procurement contract, is determined by the auction and depends on the cost of the second lowest type, type $\ddot{\theta}$. It is given by

$$
\bar{p}(\ddot{\theta})=\alpha v(\bar{x})+(1-\alpha) c(\bar{x}, \ddot{\theta})-\alpha S(\ddot{\theta}) .
$$

The ultimate price, paid by the procurer and received by the contractor, depends not only on the second lowest type but also on the lowest type $\dot{\theta}$. The procurer's ex post 
utility, for given realizations of $\dot{\theta}$ and $\ddot{\theta}$, is

$$
\begin{aligned}
u(\bar{x}, \dot{\theta}, \ddot{\theta})= & v\left(x^{*}(\dot{\theta})\right)-\bar{p}(\ddot{\theta})-\alpha\left[v\left(x^{*}(\dot{\theta})\right)-v(\bar{x})\right] \\
& -(1-\alpha)\left[c\left(x^{*}(\dot{\theta}), \dot{\theta}\right)-c(\bar{x}, \dot{\theta})\right] \\
= & (1-\alpha) S(\dot{\theta})+\alpha S(\ddot{\theta})-(1-\alpha)[c(\bar{x}, \ddot{\theta})-c(\bar{x}, \dot{\theta})] .
\end{aligned}
$$

The first part of the procurer's ex post utility can be written as $S(\ddot{\theta})+(1-\alpha)[S(\dot{\theta})-$ $S(\ddot{\theta})]$; i.e., the procurer obtains the whole surplus generated by the second most efficient type due to the competitive award procedure. On top of that, the procurer obtains the share $1-\alpha$ of the rents that are generated by the excess efficiency of type $\dot{\theta}$ compared to type $\ddot{\theta}$. This, however, is only half the story. Different supplier types benefit differently from contract renegotiation ex post. The most efficient type benefits more from contract renegotiation than the second most efficient type because he can produce design $\bar{x}$ at lower cost. Therefore, the contractor obtains a rent which equals his advantage from contract renegotiation as compared to type $\ddot{\theta}$, plus the share $\alpha$ of the additional surplus that he generates, $\alpha[S(\dot{\theta})-S(\ddot{\theta})]$.

Now, we can state the main finding of the paper.

Proposition 1. Suppose that Assumptions 1,3 hold. The procurer optimally chooses design $\bar{x}=x_{1}$ ex ante. If and only if $x^{*}(\dot{\theta}) \neq x_{1}$, renegotiation takes place and the ultimate price exceeds the initial price determined by the auction; i.e. $x^{*}(\dot{\theta}) \neq x_{1}$ $\Longleftrightarrow \hat{p}-\bar{p}>0$. Moreover, the price increase $\hat{p}-\bar{p}$ is increasing in the contractor's ex post bargaining power.

Proof. The procurer's expected utility ex ante is

$$
\mathbb{E}[u(\bar{x}, \dot{\theta}, \ddot{\theta})]=\mathbb{E}[(1-\alpha) S(\dot{\theta})+\alpha S(\ddot{\theta})-(1-\alpha)[c(\bar{x}, \ddot{\theta})-c(\bar{x}, \dot{\theta})]] .
$$

The expected utility is maximized by the design $\bar{x} \in X$ that minimizes

$$
\mathbb{E}[c(\bar{x}, \ddot{\theta})-c(\bar{x}, \dot{\theta})]
$$

By Assumption 3 the above expression is minimized for $\bar{x}=x_{1}$.

From Lemma 1 it is readily obtained that $\hat{p}-\bar{p}>0$ if renegotiation takes place and Assumption 1 holds. Moreover, from Lemma 1 it follows immediately that $\hat{p}-\bar{p}$ is increasing in $\alpha$. 
The contractor's bid already reflects that renegotiation may take place. In other words, part of the contractor's profits made by contract renegotiation are competed away in the initial auction. The profits from renegotiation that are not competed away can be decomposed into two parts. The first part is the additional surplus the contractor generates compared to the second most efficient supplier, $S(\dot{\theta})-S(\ddot{\theta})$. The second part, $c(\bar{x}, \ddot{\theta})-c(\bar{x}, \dot{\theta})$, is due to the fact that the contractor's disagreement payoff is higher than the one of the second most efficient supplier; i.e., the contractor can produce $\bar{x}$ at lower costs than all other suppliers. From the procurer's perspective, the first part is a random variable, which does not depend on her choice variable, the initial project design $\bar{x}$. The second part, on the other hand, depends on the initial design. The more complex the initial design is, the larger is the difference in disagreement payoffs between suppliers of different types. Hence, in order to minimize this difference, the procurer optimally specifies the most simple design ex ante.

\subsection{Maximum Price Bid}

Without renegotiation, a second-price auction with a maximum bid (a reserve price in a selling context) is an optimal mechanism. Proposition 1 crucially relies on the fact that the difference in production costs between the most efficient and the second most efficient type is minimized for the simplest design. If the initial price is sometimes determined by the maximum bid instead of the production costs of the second-lowest type, design $\bar{x}=x_{1}$ might not be optimal anymore. As we will show, this reasoning is not true and the simplest design is also optimal when a maximum bid is specified.

Now, we suppose the procurer specifies a maximum bid $R$; i.e., only price bids $p \leq R$ are allowed in the second-price auction. The supplier who places the lowest bid is awarded with the procurement contract. If at least two suppliers placed an admitted bid, the price equals the second lowest bid. If only one supplier placed an admitted bid, then the price equals the maximum bid $R$. As before, the contractor's type is observed by the procurer ex post and the parties may renegotiate the contract. If none of the suppliers placed an admitted bid, no initial contract is awarded. In this case, the procurer does not buy the good and there is also no (re)negotiation.

The optimal bidding strategy for a supplier who takes part in this auction with maximum bid is the same as before; i.e., a supplier of type $\theta$ places the bid

$$
\bar{p}(\theta)=\alpha v(\bar{x})+(1-\alpha) c(\bar{x}, \theta)-\alpha S(\theta) .
$$


This bid is admitted only if $\bar{p}(\theta) \leq R$. Thus, suppliers with types so that $\bar{p}(\theta)>R$ do not submit a bid. Let $r$ denote the highest type who places an admitted bid; i.e., $\bar{p}(r) \equiv R$. Notice that there is a one-to-one relationship between $R$ and $r$. Thus, we can formulate the procurer's problem as a problem of choosing a design $\bar{x}$ and threshold type $r$.

If $\bar{p}(\dot{\theta}) \leq \bar{p}(\ddot{\theta}) \leq R$, the maximum bid is not binding and the procurer's ex post utility is the same as before. If, on the other hand, $\bar{p}(\dot{\theta}) \leq R<\bar{p}(\ddot{\theta})$, then the initial price is equal to the maximum bid and thus given by

$$
R \equiv \bar{p}(r)=\alpha v(\bar{x})+(1-\alpha) c(\bar{x}, r)-\alpha S(r) .
$$

The procurer's ex post utility in this case is given by

$$
\begin{aligned}
& u(\bar{x}, \dot{\theta}, r)= v\left(x^{*}(\dot{\theta})\right)-R-\alpha\left[v\left(x^{*}(\dot{\theta})\right)-v(\bar{x})\right] \\
&-(1-\alpha)\left[c\left(x^{*}(\dot{\theta}), \dot{\theta}\right)-c(\bar{x}, \dot{\theta})\right] \\
&=\alpha S(r)+(1-\alpha) S(\dot{\theta})-(1-\alpha)[c(\bar{x}, r)-c(\bar{x}, \dot{\theta})] .
\end{aligned}
$$

For any threshold type $r \in(\underline{\theta}, \bar{\theta})$ the above expression is maximized at the simplest design $\bar{x}=x_{1}$ due to Assumption 3 . Thus, initially specifying a simple design that will probably be renegotiated to a more complex and costlier design is optimal even when a maximum bid is specified by the procurer.

Proposition 2. For any maximum bid $R \in(\bar{p}(\underline{\theta}), \bar{p}(\bar{\theta}))$, the procurer optimally chooses design $\bar{x}=x_{1}$ ex ante. If $x^{*}(\dot{\theta}) \neq x_{1}$, renegotiation takes place and the ultimate price exceeds the initial price.

\section{Scoring Auctions}

So far we assumed that the procurer has to specify the good she wants to procure completely ex ante, i.e., before the auction takes place. In the auction, the procurer collected bids only on prices and the supplier who offered the lowest price has been awarded with the contract. Different types of suppliers do not only have different production costs but also differ in the optimal design - i.e., the design that maximizes the joint surplus. Therefore, it may be profitable for the procurer to ask suppliers for bids on price and design 18

\footnotetext{
${ }^{18}$ Scoring auctions where bids are multi-dimensional (e.g. price and quality) are analyzed by Che (1993) and Asker and Cantillon (2008). An excellent short review of this literature is provided by Asker and Cantillon(2010).
} 


\subsection{The Model with Multi-Dimensional Auctions}

In the following we consider a second-score auction. Each supplier places a bid containing a price $p \in \mathbb{R}$ and a design $x \in X$. Each bid $(x, p)$ is mapped into a single score. The supplier who placed the bid giving rise to the highest score wins the auction and is required to match the highest rejected score - i.e., the second highest score. The outcome $(\bar{x}, \bar{p})$ determines a binding specific-performance contract between the procurer and the winner (the contractor). Nevertheless, this contract can be renegotiated after the auction as before.

The procurer does not choose a design when particularizing the auction. She specifies a scoring function, $G: X \times \mathbb{R} \rightarrow \mathbb{R}$, that maps bids into a single score. We focus on quasi-linear scoring functions of the form

$$
G(x, p)=g(x)-p .
$$

If the procurer can commit not to renegotiate the contract, the optimal quasi-linear scoring function implements the second-best allocation (Che, 1993). Here, the procurer cannot commit not to engage in contract renegotiation. However, as we will show below, if the scoring function represents the procurer's true preferences, i.e. $g(x) \equiv$ $v(x)$, contract renegotiation can be avoided.

\subsection{The Analysis of Multi-Dimensional Auctions}

As before, we solve the game by backward induction. The outcome of the renegotiation game is independent of the award procedure. In other words, Lemma 1 still holds and the implemented design will always be ex post efficient. Thus, the ex post utility of a supplier of type $\theta$ who has been awarded procurement contract $(\bar{x}, \bar{p})$ is

$$
\begin{aligned}
\pi(\bar{x}, \bar{p}, \theta) & =\hat{p}(\bar{x}, \bar{p}, \theta)-c\left(x^{*}(\theta), \theta\right) \\
& =\bar{p}+\alpha S(\theta)-\alpha v(\bar{x})-(1-\alpha) c(\bar{x}, \theta) .
\end{aligned}
$$

Optimal bidding behavior in the second-score auction is described by the following result.

Lemma 3. The (reduced) second-score auction game has a dominant strategy equilibrium. The equilibrium bid of each supplier of type $\theta$ is

$$
\begin{aligned}
& x^{b}(\theta) \in \arg \max _{x \in X}\{g(x)-\alpha v(x)-(1-\alpha) c(x, \theta)\}, \\
& p^{b}(\theta)=\alpha v\left(x^{b}(\theta)\right)+(1-\alpha) c\left(x^{b}(\theta), \theta\right)-\alpha S(\theta) .
\end{aligned}
$$


By Lemma 3, each supplier bids the optimal design, $x^{b}(\theta)=x^{*}(\theta)$, if the scoring function represents the procurer's true preferences - i.e., if $v(x) \equiv g(x)$. If, on the other hand, the scoring function does not reflect the true preferences of the procurer, then it is likely that suppliers propose designs that are not efficient.

According to Lemma 3, the score offered by a supplier of type $\theta$ amounts to

$$
\begin{aligned}
G(\theta) & \equiv g\left(x^{b}(\theta)\right)-p^{b}(\theta) \\
& =g\left(x^{b}(\theta)\right)-\alpha v\left(x^{b}(\theta)\right)-(1-\alpha) c\left(x^{b}(\theta), \theta\right)+\alpha S(\theta) .
\end{aligned}
$$

As before, the most efficient type places the bid that leads to the highest score and thus wins the auction.

Lemma 4. Suppose that Assumption 2 holds. Then for all $\theta_{1}<\theta_{2}$ it holds that:

$$
G\left(\theta_{1}\right)>G\left(\theta_{2}\right)
$$

The winner of the auction, type $\dot{\theta}$, has to match the second highest score but is otherwise free in its choice of $(\bar{x}, \bar{p})$. Thus, the winner of the auction chooses the initial contract $(\bar{x}, \bar{p})$ in order to maximize

$$
\bar{p}+\alpha S(\dot{\theta})-\alpha v(\bar{x})-(1-\alpha) c(\bar{x}, \theta)
$$

subject to $g(\bar{x})-\bar{p}=G(\ddot{\theta})$. Hence, the initial contract specifies $\bar{x}(\dot{\theta}, \ddot{\theta})=x^{b}(\dot{\theta})$ and $\bar{p}(\dot{\theta}, \ddot{\theta})=g\left(x^{b}(\dot{\theta})\right)-G(\ddot{\theta})$. The ultimate price paid by the procurer is

$$
\begin{aligned}
& \hat{p}(\dot{\theta}, \ddot{\theta})=g\left(x^{b}(\dot{\theta})\right)-g\left(x^{b}(\ddot{\theta})\right)+\alpha v\left(x^{b}(\ddot{\theta})\right)+(1-\alpha) c\left(x^{b}(\ddot{\theta}), \ddot{\theta}\right) \\
&-\alpha S(\ddot{\theta})+\alpha\left[v\left(x^{*}(\dot{\theta})\right)-v\left(x^{b}(\dot{\theta})\right)\right] \\
&+(1-\alpha)\left[c\left(x^{*}(\dot{\theta}), \dot{\theta}\right)-c\left(x^{b}(\dot{\theta}), \dot{\theta}\right)\right] .
\end{aligned}
$$

\subsection{The Optimality of Price-Only Auctions}

The procurer's ex post utility - for given realizations of $\dot{\theta}$ and $\ddot{\theta}$ - is given by

$$
\begin{aligned}
u(\dot{\theta}, \ddot{\theta})= & v\left(x^{*}(\dot{\theta})\right)-\hat{p}(\dot{\theta}, \ddot{\theta}) \\
= & (1-\alpha) S(\dot{\theta})+\alpha S(\ddot{\theta}) \\
& +\left\{g\left(x^{b}(\ddot{\theta})\right)-\alpha v\left(x^{b}(\ddot{\theta})\right)-(1-\alpha) c\left(x^{b}(\ddot{\theta}), \ddot{\theta}\right)\right\} \\
& -\left\{g\left(x^{b}(\dot{\theta})\right)-\alpha v\left(x^{b}(\dot{\theta})\right)-(1-\alpha) c\left(x^{b}(\dot{\theta}), \dot{\theta}\right)\right\} .
\end{aligned}
$$


The procurer chooses the scoring function $g(\cdot)$ that maximizes her expected payoff $\mathbb{E}[u(\dot{\theta}, \ddot{\theta})]$. As it turns out, a constant scoring function - i.e., a scoring rule that depends only on the price - is optimal.

Proposition 3. Suppose Assumptions 13 hold. Then, the optimal quasi-linear scoring rule is independent of the design, i.e., $g(x)=\bar{g} \in \mathbb{R}$. Each supplier $\theta$ bids the design $x^{b}(\theta)=x_{1}$. Renegotiation takes place if $x^{*}(\dot{\theta}) \neq x_{1}$. In this case, the ultimate price exceeds the initial price, $\hat{p}-\bar{p}>0$.

Proof. Define

$$
A(x, \theta) \equiv g(x)-\alpha v(x)-(1-\alpha) c(x, \theta)
$$

and notice that $A(x, \theta)$ is maximized at $x=x^{b}(\theta)$. Moreover, for all $\theta_{1}<\theta_{2}$ it holds that

$$
A\left(x^{b}\left(\theta_{1}\right), \theta_{1}\right) \geq A\left(x^{b}\left(\theta_{2}\right), \theta_{2}\right),
$$

irrespective of the shape of the scoring function $g(\cdot)$. The procurer's maximization problem can be restated as:

$$
\min \quad \mathbb{E}_{\dot{\theta}, \ddot{\theta}}\left[A\left(x^{b}(\dot{\theta}), \dot{\theta}\right)-A\left(x^{b}(\ddot{\theta}), \ddot{\theta}\right)\right]
$$

Note that

$$
A\left(x^{b}(\dot{\theta}), \dot{\theta}\right)-A\left(x^{b}(\ddot{\theta}), \ddot{\theta}\right) \geq(1-\alpha)\left[c\left(x^{b}(\ddot{\theta}), \ddot{\theta}\right)-c\left(x^{b}(\ddot{\theta}), \dot{\theta}\right)\right]
$$

The left-hand side coincides with the right-hand side if $x^{b}(\dot{\theta})=x^{b}(\ddot{\theta})$. Moreover, by Assumption 3 , the right-hand side - the lower bound - is minimized if $x^{b}(\ddot{\theta})=x_{1}$. Thus, if for all possible $\dot{\theta} \leq \ddot{\theta}$ we have $x^{b}(\dot{\theta})=x^{b}(\ddot{\theta})=x_{1}$, then the corresponding $g(\cdot)$ function is a solution to the above minimization problem. For $g(x)=\bar{g}$, each supplier bids the design $x_{1}$. This follows from Lemma 3 and Assumption 1 . Hence, $G(x, p)=-p$ is an optimal scoring function.

The price mark-up in case renegotiation takes place is

$$
\hat{p}(\dot{\theta}, \ddot{\theta})-\bar{p}=\alpha\left[v\left(x^{*}(\dot{\theta})\right)-v\left(x^{b}(\dot{\theta})\right)\right]+(1-\alpha)\left[c\left(x^{*}(\dot{\theta}), \dot{\theta}\right)-c\left(x^{b}(\dot{\theta}), \dot{\theta}\right)\right],
$$

where $x^{b}(\dot{\theta})=x_{1}$. Hence, if $x^{*}(\dot{\theta}) \neq x_{1}$ - renegotiation takes place, then $\hat{p}-\bar{p}>0$, by Assumption 1 . 
According to Proposition 3, if the buyer is unable to commit not to renegotiate, she cannot benefit from using a scoring auction. A scoring auction by its multi-dimensionality allows suppliers to differentiate their bids, which reduces price competition. In other words, a more efficient supplier can offer a design that leads to a higher score than a less efficient supplier. By doing so the more efficient supplier may be able to win the auction even if his price bid is relatively high. This makes the usage of a scoring auction expensive and thus less attractive to the procurer. Hence, a simple auction where the procurer collects price bids for a given design is optimal. The given design is rather simple, so that the differences between suppliers regarding their costs for delivering this design are relatively low. This enhances the competition at the auction stage and leads to a very low initial price. Even though the ex post price can be significantly higher than the initial price, the effect on the initial price dominates.

Moreover, Proposition 3 implies that avoiding renegotiation by specifying an appropriate scoring function is not in the procurer's best interest.

Corollary 1. For $\alpha \in(0,1)$ the procurer strictly prefers the optimal simple secondprice auction, i.e., fixing $\bar{x}=x_{1}$ to the second-score auction with the scoring function reflecting her true preferences, i.e., to $g(x) \equiv v(x)$.

If the scoring function represents the procurer's true preferences, each supplier $\theta$ bids the efficient design $x^{*}(\theta)$. In this case, there is no scope for renegotiation. Avoiding renegotiation, however, is not in the procurer's interest. This is due to the fact that we assume efficient - Coasian - bargaining ex post and that the gains from renegotiation are incorporated in the initial price bids.

\section{Discussion and Extensions}

\subsection{Discussion of Our Main Assumptions}

Strikingly as the findings are, they rely on a couple of strong assumptions. First, we assume that there is a design that is relatively cheap to produce for all types and the differences in production costs between types are lowest for this design. If the differences in production costs across types are lowest for a more expensive design, specifying the cheapest design ex ante is no longer optimal. A potential micro foundation of our assumption might be the following: Suppose that designs consist of different components. The more complex a design, the more components it consists of. If suppliers 
draw a random cost type for all of the components rather than just one overall type, the expected cost differences are larger for more complex projects.

Second, and related to the point above, suppliers' preferences regarding designs are aligned; i.e., a change in the design leads either to a cost increase or decrease for all suppliers. To see the importance of this assumption imagine that - for the sake of the argument - all designs give rise to the same gross benefit. A supplier's type determines which design the supplier can deliver at lowest cost. Now, specifying one design ex ante reduces competition and leads to a high ultimate price. A scoring auction is now likely to be optimal because it enhances competition. Our assumption that cost are perfectly aligned is sufficient but not necessary for our results. Allowing for "weakly" aligned costs makes the analysis more tedious without adding much insight.

Third, the suppliers anticipate the contract renegotiation and incorporate the potential ex post profits in their ex ante bid. This, however, implies that if the initial contract is enforced - because the parties could not find an agreement at the renegotiation stage the contractor may make a loss and is able to cover this loss. If suppliers are protected by limited liability, the initial price is bounded from below by the production cost. Due to this price bound, the supplier's outside option at the renegotiation stage is now more valuable. Hence, renegotiation becomes more expensive for the procurer and thus she may have an incentive to specify a design which is close to the ex post efficient design.

Fourth, we assume that renegotiation takes place under symmetric information 19 Suppose the contractor's cost type is private information ex post and that either the procurer or the contractor can make a take-it-or-leave-it offer at the renegotiation stage. Now, the optimal renegotiation offer of the procurer might be such that it is rejected by certain supplier types. If this is the case, then the initial contract is executed. Thus, auctioning off the simplest design which creates only little value to the procurer is likely to be suboptimal if there is a high chance that the initial contract will be executed due to a breakdown of renegotiation. This story is true, however, only if the procurer cannot deduce the contractor's type from the initial bid. The game is now a signaling game, where the initial bid may contain information about the supplier's type. If there is a fully separating equilibrium, contract renegotiation basically takes place under full information. Thus, behavior at the renegotiation stage is as in our model with com-

\footnotetext{
${ }^{19}$ Assuming that suppliers' types are public information already ex ante does not change our main results.
} 
plete information. Suppliers' bidding behavior ex ante might nevertheless be different. An analysis of procurement with contract renegotiation under asymmetric information, which involves solving an intricate signaling game, is beyond the scope of this paper.

Renegotiation can be imperfect for reasons different from asymmetric information. This is discussed in detail in the following subsection.

\subsection{Risk of Breakdown of Renegotiation}

So far we assumed that ex post the parties engage in Coasian bargaining. In other words, the ex post efficient design is always implemented; i.e., there are neither adjustment costs of contract renegotiation nor a risk that renegotiation fails. In the following, we will show that our main findings are robust toward introducing frictions of contract renegotiation.

We model the imperfection of contract renegotiation in the following simple way. With fixed exogenous probability $b \in[0,1)$ the parties cannot reach an agreement ex post - i.e., renegotiation fails. In this case the initial contract $(\bar{x}, \bar{p})$ is executed. With the converse probability $1-b$ the parties reach an agreement and the outcome is determined by the GNBS. The parameter $b$ measures how intricate or how costly contract renegotiation is. For $b=0$ the model collapses to the one previously analyzed ${ }^{20}$

The analysis of the model with a risk of renegotiation breakdown proceeds by the same steps as the analysis of Section 3 .

Proposition 4. Suppose that Assumptions 1,3 hold and that renegotiation fails with probability $b \in[0,1)$. The procurer optimally chooses the design $\bar{x}$ that solves

$$
\left.\max _{\bar{x}} \mathbb{E}_{\dot{\theta}, \ddot{\theta}}[b[v(\bar{x}))-c(\bar{x}, \ddot{\theta})]-(1-\alpha)(1-b)[c(\bar{x}, \ddot{\theta})-c(\bar{x}, \dot{\theta})]\right] .
$$

The procurer now faces a trade-off. On the one hand, as before, she wants to minimize the cost advantage that the most efficient supplier has in comparison to the second most efficient supplier in the production of design $\bar{x}$. This is achieved by setting $\bar{x}=x_{1}$. On the other hand, the procurer has an incentive to choose as initial design the design that is optimal when the second most efficient supplier obtains the contract. This is intuitive because if renegotiation fails the procurer obtains the surplus that is generated

\footnotetext{
${ }_{20}$ Ganuza (2007) uses the same approach to model transaction costs of contract renegotiation. In his interpretation there are transaction costs associated with renegotiation and these costs are stochastic. With probability $1-b$ the transaction costs are zero, while with probability $b$ the transaction costs are prohibitively high so that renegotiation does not take place.
} 
by the second most efficient type. This is likely to be achieved by a design $\bar{x}$ which is more complex than design $x_{1}$. If $b$ is sufficiently low, the former concern dominates the latter and $\bar{x}=x_{1}$ is optimal. As the risk of renegotiation failure increases, the optimal ex ante design becomes (weakly) more complex. ${ }^{21}$

If $\bar{x} \neq x_{1}$ is optimal, the ex post renegotiation can lead to an upward as well as downward price adjustment. The latter occurs if the most efficient type happens to be rather inefficient. How likely upward and downward price adjustments are, is intricate to characterize without further assumptions on the type distribution and the feasible designs. Therefore, we will present the results of a simple numerical example in the following. Let $\rho^{U}:=\operatorname{Prob}\left(x^{*}(\dot{\theta})>\bar{x}\right)$; i.e., it is the (conditional) probability with which renegotiation leads to an upward price adjustment (a cost overrun occurs).

Example 1. Let the cost function be $c(x, \theta)=(1 / 2) \theta x^{2}$ and the value function be $v(x)=x$. The set of feasible designs is assumed to be continuous and given by $X=$ $[1 / 2,1]$, with $x_{1}=1 / 2$. The types of the $n \geq 2$ sellers are drawn independently from the uniform distribution with support $[1,2]$. The ex post efficient design is $x^{*}(\theta)=$ $1 / \theta \in[1 / 2,1]$.

The procurer optimally specifies design

$$
\bar{x}=\max \left\{\frac{1}{2}, \frac{b(1+n)}{1-\alpha+b(2+\alpha+n)}\right\}
$$

in the initial auction. The initial design is equal to the simplest design, $\bar{x}=x_{1}=1 / 2$ if $b \leq \hat{b}$, where

$$
\hat{b}:=\frac{1-\alpha}{n-\alpha} .
$$

Notice that for $\alpha<1$ the critical probability of breakdown $\hat{b}$ is strictly greater than zero. In other words, for a range of b-values specifying the simplest design initially is optimal.

A cost overrun - an upward price adjustment - occurs ex post if $x^{*}(\theta)>\bar{x}$, which is equivalent to $\dot{\theta}<\bar{x}^{-1}$. The probability of a cost overrun is bounded from below,

$$
\rho^{U} \geq 1-\frac{1}{\mathrm{e}^{2}} \approx 0.865
$$

where e is Euler's number:22

\footnotetext{
${ }^{21}$ We can interpret $b$ as a bargaining inefficiency parameter. As renegotiation becomes more costly, the optimal ex ante design becomes (weakly) more complex.

${ }^{22}$ Detailed calculations to Example 1 are presented in the Appendix $\mathrm{A}$
} 
The example illustrates that even when there is a risk of renegotiation failure - and thus a rational for the procurer to choose a more complex design than $x_{1}$ - ex post adjustments typically lead to the implementation of a more complex and costlier design. Thus, if renegotiation takes place, an upward price adjustment is extremely likely. In the example, if renegotiation takes place the final price exceeds the initial price in more than $86 \%$ of the cases. Downward price adjustments are unlikely and occur in less than $14 \%$ of the cases. At first glance, these percentages may seem somewhat extreme. It is useful to remember that the procurer maximizes

$$
\mathbb{E}_{\ddot{\theta}}[v(\bar{x})-c(\bar{x}, \ddot{\theta})],
$$

if renegotiation is very costly or her bargaining power is very low. The $\bar{x}$ that maximizes (23) is the most complex initial design that can be optimal. The more complex the design is, the less likely is a cost overrun ex post. The term (23) is maximized for the design at which the surplus generated by the second most efficient type is maximized in expectations. With the most efficient type being likely to be more efficient than the expected second most efficient type, even in this extreme situation upward adjustments are more likely than downward adjustments ${ }^{23}$ This explains why the lower bound on the conditional likelihood of a cost overrun is so high.

\section{Conclusion}

We analyzed competitive procurement mechanisms in an environment where the procurer is unable to commit not to renegotiate the contract ex post. Moreover, the cost function of the supplier who has been awarded with the initial contract is publicly observed ex post. Hence, if the initial design turns out to be ex post inefficient - for the given cost function - the parties adjust the initial design to the ex post efficient one; i.e., the parties engage in Coasian bargaining. The main finding is that the constraint optimal award procedure is a simple auction. The procurer awards the contract for the simplest design via a standard auction. Ex post, a more complex and more costly design is implemented and thus the ultimate price typically is higher than the initial price determined by the auction. Interestingly, the optimal simple auction where the procurer collects only price bids for the simplest design outperforms multi-dimensional auctions, where a bid contains a price and a design. The reason is that a mulit-dimensional

\footnotetext{
${ }^{23}$ This intuition holds true only for "nice" type distributions like the uniform distribution.
} 
auction reduces competition between the suppliers ex ante.

The finding that it is optimal to auction off the simplest design when using a priceonly auction holds true also when the procurer can set a maximum bid. When renegotiation is inefficient or there is a risk it might breakdown, the optimal ex ante design is not necessarily the most simple one any more. However, as we demonstrate in an example, the optimal ex ante design still has a strong tendency to be relatively simple (simpler than the optimal ex post design) so that renegotiation typically leads to an upward price adjustment.

The findings of the paper rely on a couple of strong assumptions that often will not all be satisfied in practice. Hence, we do not argue based on these results that most of the projects with severe cost overruns that we observe in practice are always the result of efficient award procedures. However, our main assumption that commitment not to renegotiate is not feasible seems to be realistic. For instance, complex construction projects often cannot be executed exactly the way as initially specified, so contract renegotiation has to take place. This paper shows that severe cost overruns are not necessarily a sign of inefficient award procedures or project completion.

\section{A. Proofs and Calculations}

Proof of Lemma 1. First, we show that the parties agree to trade $x^{*}(\theta)$. In contradiction, let $(\hat{x}, \hat{p})$ with $\hat{x} \neq x^{*}(\theta)$ be the outcome of renegotiation. The resulting generalized Nash product is

$$
\operatorname{GNP}(\hat{x}, \hat{p})=\left[\hat{p}-c(\hat{x}, \theta)-d_{C}\right]^{\alpha} \times\left[v(\hat{x})-\hat{p}-d_{P}\right]^{1-\alpha} .
$$

Consider the alternative contract with design $x^{*}(\theta)$ and price $p^{*}=\hat{p}+v\left(x^{*}(\theta)\right)-v(\hat{x})$. By construction, the procurer is indifferent between the two contracts. The contractor's net payoff under the alternative contract is

$$
p^{*}-c\left(x^{*}(\theta), \theta\right)-d_{C} \text {. }
$$

Hence, the contractor prefers the alternative contract if and only if

$$
\begin{aligned}
\hat{p}+v\left(x^{*}(\theta)\right)-c\left(x^{*}(\theta), \theta\right)-v(\hat{x})-d_{C} & \geq \hat{p}-c(\hat{x}, \theta)-d_{C} \\
\Longleftrightarrow v\left(x^{*}(\theta)\right)-c\left(x^{*}(\theta), \theta\right) & \geq v(\hat{x})-c(\hat{x}, \theta),
\end{aligned}
$$


which holds by the definition of $x^{*}(\theta)$ and the fact that $\bar{x}$ does not maximize the social surplus. Thus, $\operatorname{GNP}\left(x^{*}(\theta), p^{*}\right)>G N P(\hat{x}, \hat{p})$ a contradiction to the assumption that $(\hat{x}, \hat{p})$ is the outcome of renegotiation.

Taking the partial derivative of the generalized Nash product with respect to $p$ yields

$$
\begin{aligned}
& \frac{\partial G N P}{\partial p}=\alpha\left[\frac{v\left(x^{*}(\theta)\right)-p-v(\bar{x})+\bar{p}}{p-c\left(x^{*}(\theta), \theta\right)-\bar{p}+c(\bar{x}, \theta)}\right]^{\alpha} \\
& -(1-\alpha)\left[\frac{p-c\left(x^{*}(\theta), \theta\right)-\bar{p}+c(\bar{x}, \theta)}{v\left(x^{*}(\theta)\right)-p-v(\bar{x})+\bar{p}}\right]^{1-\alpha} .
\end{aligned}
$$

We set the partial derivative equal to zero and solve for the renegotiation price

$$
\hat{p}=\bar{p}+\alpha\left[v\left(x^{*}(\theta)\right)-v(\bar{x})\right]+(1-\alpha)\left[c\left(x^{*}(\theta), \theta\right)-c(\bar{x}, \theta)\right] .
$$

Proof of Lemma 2. It is a well-known result that in a second-price auction it is a (weakly) dominant strategy for each bidder to bid his type. Placing a bid equal to the type, corresponds to placing a price bid so that the profit equals zero in our setup. Placing a higher bid reduces the probability of winning the auction without affecting the price $\bar{p}$. A lower bid is not optimal because in the additional cases where the supplier now wins the auction, he makes losses.

It remains to be shown that $\theta_{1}<\theta_{2}$ implies $\bar{p}\left(\theta_{1}\right)<\bar{p}\left(\theta_{2}\right)$. This property of the bidding function follows immediately from Assumption 2. Note that $S(\theta) \equiv$ $\max _{x}\{v(x)-c(x, \theta)\}$ and thus $S\left(\theta_{1}\right)>S\left(\theta_{2}\right)$ by Assumption 2 .

Proof of Proposition 2. It is readily established that the bidding strategy $\bar{p}(\theta)$ for types $\theta \leq r$ constitutes a Nash equilibrium of the (reduced) auction game. Thus, the procurer maximizes the following expression via the design $\bar{x}$ and the threshold type $r$ :

$$
\begin{aligned}
& \int_{\underline{\theta}}^{r} \int_{\underline{\theta}}^{\ddot{\theta}}[(1-\alpha) S(\dot{\theta})+\alpha S(\ddot{\theta})-(1-\alpha)[c(\bar{x}, \ddot{\theta})-c(\bar{x}, \dot{\theta})]] \\
& n(1-F(\dot{\theta}))^{n-1} f(\dot{\theta}) n(n-1)(1-F(\ddot{\theta}))^{n-2} F(\ddot{\theta}) f(\ddot{\theta}) d \dot{\theta} d \ddot{\theta} \\
& +\int_{r}^{\bar{\theta}} \int_{\underline{\theta}}^{r}[(1-\alpha) S(\dot{\theta})+\alpha S(r)-(1-\alpha)[c(\bar{x}, r)-c(\bar{x}, \dot{\theta})]] \\
& n(1-F(\dot{\theta}))^{n-1} f(\dot{\theta}) n(n-1)(1-F(\ddot{\theta}))^{n-2} F(\ddot{\theta}) f(\ddot{\theta}) d \dot{\theta} d \ddot{\theta} .
\end{aligned}
$$

The first summand describes the situation when the second-lowest bid is below the maximum bid, while the second summand describes the situation when the maximum 
bid binds for determining the price. Since this expression is decreasing in $[c(\bar{x}, \ddot{\theta})-$ $c(\bar{x}, \dot{\theta})]$ and $[c(\bar{x}, r)-c(\bar{x}, \dot{\theta})]$, an optimal solution requires $\bar{x}=x_{1}$ by Assumption 3 .

Proof of Lemma 3 Each supplier has an incentive to place the bid $\left(x^{b}, p^{b}\right)$ that maximizes the score $G(x, p)$ subject to the supplier's break-even constraint.

Bidding a lower score reduces the probability of winning without affecting the concluded contract in case the supplier wins the auction. As in a second-price auction, the concluded contract is independent of the bid placed by the winner.

Bidding a higher score increases the probability of winning. In the additional cases where the supplier now wins, he has to match a score at which he makes losses.

Hence, the optimal bid solves:

$$
\begin{array}{ll}
\max _{x, p} & g(x)-p \\
\text { s.t. } & p+\alpha S(\theta)-\alpha v(x)-(1-\alpha) c(x, \theta) \geq 0 .
\end{array}
$$

The solution is $x^{B}(\theta)$ and $p^{b}(\theta)$, which concludes the proof; see also Che (1993).

Proof of Lemma 4

$$
\begin{gathered}
G\left(\theta_{2}\right)=g\left(x^{b}\left(\theta_{2}\right)\right)-\alpha v\left(x^{b}\left(\theta_{2}\right)\right)-(1-\alpha) c\left(x^{b}\left(\theta_{2}\right), \theta_{2}\right)+\alpha S\left(\theta_{2}\right) \\
<g\left(x^{b}\left(\theta_{2}\right)\right)-\alpha v\left(x^{b}\left(\theta_{2}\right)\right)-(1-\alpha) c\left(x^{b}\left(\theta_{2}\right), \theta_{1}\right)+\alpha S\left(\theta_{1}\right) \\
\leq g\left(x^{b}\left(\theta_{1}\right)\right)-\alpha v\left(x^{b}\left(\theta_{1}\right)\right)-(1-\alpha) c\left(x^{b}\left(\theta_{1}\right), \theta_{1}\right)+\alpha S\left(\theta_{1}\right) \\
=G\left(\theta_{1}\right) .
\end{gathered}
$$

The first inequality follows from Assumption 2 and the second inequality holds by the definition of $x^{b}(\cdot)$.

Proof of Corollary 1$]$ Follows immediately from Proposition 3.

Proof of Proposition 4. If renegotiation takes place, then the outcome is characterized by Lemma 1 . The expected ex post utility of the contractor from contract $(\bar{x}, \bar{p})$ is

$$
\begin{aligned}
\pi(\bar{x}, \bar{p}, \theta) & =(1-b)\left[\hat{p}(\bar{p}, \theta)-c\left(x^{*}(\theta), \theta\right)+b[\bar{p}-c(\bar{x}, \theta)]\right. \\
& =\bar{p}+(1-b) \alpha[S(\theta)-v(\bar{x})]-[1-\alpha(1-b)] c(\bar{x}, \theta)
\end{aligned}
$$

From the above expression the next result is readily obtained. 
Lemma 5. The symmetric equilibrium bidding strategy is

$$
\bar{p}(\theta)=(1-b) \alpha[v(\bar{x})-S(\theta)]+[1-\alpha(1-b)] c(\bar{x}, \theta) .
$$

The above lemma can be proven by the usual steps (as in the proof of Lemma 2).

The most efficient type $\dot{\theta}$ wins the auction and the initial price is determined by the second most efficient type $\ddot{\theta}$, which is given by

$$
\bar{p}(\ddot{\theta})=(1-b) \alpha[v(\bar{x})-S(\ddot{\theta})]+[1-\alpha(1-b)] c(\bar{x}, \ddot{\theta}) .
$$

The final price is given by

$$
\begin{aligned}
& \hat{p}(\dot{\theta}, \ddot{\theta})=\alpha(1-b) v(\bar{x})-\alpha(1-b) S(\ddot{\theta})+[1-\alpha(1-b)] c(\bar{x}, \ddot{\theta}) \\
&+\alpha\left[v\left(x^{*}(\dot{\theta})\right)-v(\bar{x})\right]+(1-\alpha)\left[c\left(x^{*}(\dot{\theta}), \dot{\theta}\right)-c(\bar{x}, \dot{\theta})\right] .
\end{aligned}
$$

The procurer's ex post utility for given realizations of $\dot{\theta}$ and $\ddot{\theta}$ is

$$
u(\bar{x}, \dot{\theta}, \ddot{\theta})=b[v(\bar{x})-\bar{p}(\ddot{\theta})]+(1-b)\left[v\left(x^{*}(\dot{\theta})-\hat{p}(\dot{\theta}, \ddot{\theta})\right] .\right.
$$

Inserting the expressions for $\hat{p}$ and $\bar{p}$ in the procurer's utility and rearranging yields

$$
\begin{aligned}
u(\bar{x}, \dot{\theta}, \ddot{\theta})=(1-b) & {[(1-\alpha) S(\dot{\theta})+\alpha S(\ddot{\theta})] } \\
& -(1-b)(1-\alpha)[c(\bar{x}, \ddot{\theta})-c(\bar{x}, \dot{\theta})]+b[v(\bar{x})-c(\bar{x}, \ddot{\theta})] .
\end{aligned}
$$

Noting that the procurer maximizes $\mathbb{E}[u(\bar{x}, \dot{\theta}, \ddot{\theta})]$ by choosing $\bar{x}$ completes the proof.

Supplementary Calculations to Example 1. The first-order condition of the procurer's maximization problem is

$$
\mathbb{E}_{\dot{\theta}, \ddot{\theta}}[b[1-\ddot{\theta} \bar{x}]-(1-\alpha)(1-b) \bar{x}(\ddot{\theta}-\dot{\theta})]=0 .
$$

When an interior solution exists, i.e $\bar{x}>1 / 2$ is optimal, then this solution satisfies the first-order condition. By using the distribution of the lowest and the second lowest type realization (order statistics), the first-order condition can be written as

$$
\begin{aligned}
\int_{1}^{2}[b(1-\ddot{\theta} \bar{x})-(1-\alpha)(1-b) \ddot{\theta} \bar{x}] n(n-1)(\ddot{\theta}-1)(2-\ddot{\theta})^{n-2} d \ddot{\theta} \\
+\int_{1}^{2}(1-\alpha)(1-b) \dot{\theta} \bar{x} n(2-\dot{\theta})^{n-1} d \dot{\theta}=0 .
\end{aligned}
$$


Solving the above expression for $\bar{x}$ yields

$$
\bar{x}=\frac{b(1+n)}{1-\alpha+b(2+\alpha+n)}<1 .
$$

A corner solution, $\bar{x}=x_{1}=1 / 2$, is optimal if

$$
1-\alpha(1-b)-b n \geq 0
$$

which is equivalent to

$$
b \leq \frac{1-\alpha}{n-\alpha}<1
$$

Notice that for $\alpha<1$ the critical $b$ is strictly positive.

An important observation is that $\bar{x}$ is increasing in $b$. Thus, the highest $\bar{x}$ is selected for $b \rightarrow 1$. For $b \rightarrow 1$ (or $\alpha \rightarrow 1$ ), we obtain

$$
\bar{x}=\frac{1+n}{3+n}>\frac{1}{2},
$$

which is the socially optimal design for the expected second lowest type. If the probability of bargaining breakdown is sufficiently high, specifying the simplest design ex ante is not optimal. Now, renegotiation may lead to a downward as well as to an upward adjustment of $x$ ex post. Upward renegotiation takes place if $x^{*}(\dot{\theta})>\bar{x}$, which is equivalent to $(b=1)$

$$
\dot{\theta}<\frac{3+n}{1+n} .
$$

Hence, the probability with which a cost overrun occurs is $\rho^{U}=\operatorname{Prob}(\dot{\theta}<(3+n) /(1+$ $n)$. Due to the continuous design, the probability of a downward adjustment ex post is $\rho^{D}=1-\rho^{U}$. Hence, a cost overrun occurs ex post with probability

$$
\rho^{U}(n)=F_{(1)}\left(\frac{3+n}{1+n}\right)=1-\left(2-\frac{3+n}{1+n}\right)^{n}=1-\left(\frac{n-1}{n+1}\right)^{n},
$$

where $F_{(1)}(\cdot)$ denotes the c.d.f. of the lowest type realization. Importantly, $\rho^{U}(n)$ is decreasing in $n$ and

$$
\lim _{n \rightarrow \infty} \rho^{U}(n)=1-\frac{1}{\mathrm{e}^{2}} \approx 0.865
$$

where e is Euler's number.

\section{References}

Asker, J., AND E. CANTILlon (2008): "Properties of scoring auctions," The RAND Journal of Economics, 39(1), 69-85. 
(2010): "Procurement when price and quality matter," The RAND Journal of Economics, 41(1), 1-34.

BAJARi, P., S. Houghton, And S. TAdelis (2014): "Bidding for Incomplete Contracts: An Empirical Analysis of Adaptation Costs," The American Economic Review, 104(4), 1288-1319.

BAJARI, P., AND S. TADELIS (2001): "Incentives versus Transaction Costs: A Theory of Procurement Contracts," The RAND Journal of Economics, 32(3), 87-407.

Beaudry, P., And M. Poitevin (1995): "Contract Renegotiation: A Simple Framework and Implications for Organization Theory," The Canadian Journal of Economics / Revue canadienne d'Economique, 28(2), pp. 302-335.

Binmore, K., A. Rubinstein, And A. Wolinsky (1986): “The Nash Bargaining Solution in Economic Modelling," The RAND Journal of Economics, 17(2), 176188.

Birulin, O. (2014): “Optimal Auctions of Procurement Contracts,” Working Paper, University of Sydney.

Birulin, O., And S. Izmalkov (2013): “On Cost Overruns in Procurement,” Working Paper, University of Sydney.

Burguet, R., J.-J. GANuZA, And E. HAUK (2012): “Limited liability and mechanism design in procurement," Games and Economic Behavior, 76(1), 15 - 25.

Chang, W.-S., T. SAlmon, And K. J. SARAL (2014): "Procurement Auctions with Renegotiation and Wealth Constraints," Available at SSRN: http://ssrn.com/ abstract $=2330106$.

CHE, Y.-K. (1993): "Design competition through multidimensional auctions," RAND Journal of Economics, 24(4), 668-680.

Chen-Ritzo, C.-H., T. P. Harrison, A. M. Kwasnica, and D. J. Thomas (2005): "Better, Faster, Cheaper: An Experimental Analysis of a Multiattribute Reverse Auction Mechanism with Restricted Information Feedback," Management Science, 51(12), 1753-1762. 
Crocker, K. J., AND K. J. Reynolds (1993): "The Efficiency of Incomplete Contracts: An Empirical Analysis of Air Force Engine Procurement," The RAND Journal of Economics, 24(1), 126-146.

Dasgupta, S., And D. F. Spulber (1989-1990): "Managing procurement auctions," Information Economics and Policy, 4(1), 5 - 29.

DeCARolis, F. (2014): “Awarding Price, Contract Performance, and Bids Screening: Evidence from Procurement Auctions," American Economic Journal: Applied Economics, 6(1), 108-132.

Drew, P. (1999): The Masterpiece: Jørn Utzon, A Secret Life. Hardie Grant Books, Richmond (VIC), Australia.

GanuZA, J.-J. (2007): “Competition and Cost Overruns in Procurement,” The Journal of Industrial Economics, 55(4), 633-660.

Harstad, R. M., AND M. H. RothKopf (1995): "Withdrawable Bids as Winner's Curse Insurance," Operations Research, 43(6), 983-994.

Herweg, F., And K. M. Schmidt (2014): “Auctions vs. Negotiations: The Effects of Inefficient Renegotiation," CEPR Discussion Paper No. DP10284. Available at SSRN: http: //ssrn.com/abstract $=2535421$.

KostKa, G., And N. AnZinger (2015): "Large Infrastructure Projects in Germany: Between Ambition and realities," Working Paper, Hertie School of Governance.

KrishnA, V. (2010): Auction Theory. Academic Press, Elsevier, Heidelberg.

Laffont, J.-J., And J. Tirole (1993): A Theory of Incentives in Procurement and Regulation. MIT Press, Cambridge.

Muthoo, A. (1999): Bargaining Theory with Applications. Cambridge University Press, Cambridge.

Newton, S., M. Skitmore, And P. Love (2014): "Managing Uncertainty to Improve the Cost Performance of Complex Infrastructure Projects," in Construction in a Changing World, ed. by D. Amaratunga, R. Haigh, L. Ruddock, K. Keraminiyage, U. Kulatunga, and C. Pathirage, Sri Lanka. University of Salford. 
Roelofs, M. R. (2002): "Common Value Auctions with Default: An Experimental Approach," Experimental Economics, 5(3), 233-252.

SALOP, S. C. (1979): "Monopolistic Competition with Outside Goods," The Bell Journal of Economics, 10(1), pp. 141-156.

SHACHAT, J., AND L. TAN (2015): “An Experimental Investigation of Auctions and Bargaining in Procurement," Management Science, 61(5), 1036-1051.

Tirole, J. (1986): “Procurement and Renegotiation,” Journal of Political Economy, 94(2), 235-259.

Waehrer, K. (1995): “A Model of Auction Contracts with Liquidated Damages," Journal of Economic Theory, 67(2), 531 - 555.

WANG, R. (2000): "Bidding and renegotiation in procurement auctions," European Economic Review, 44(8), 1577 - 1597. 